\section{ALTERAÇÕES AUTOBIOGRÁFICAS EM MULHERES VITIMADAS ATENDIDAS PELA REDE DE ACOLHIMENTO}

\author{
Autobiographical Changes in Women Victimized Served by \\ Public Care Network
}
Alteraciones Autobiográficas de Mujeres Víctimas Asistidas en la Red de Acogida
Changement Autobiographiques des Femmes Victimes Desservies par le Réseau D'accueil

\begin{abstract}
Resumo
A violência contra a mulher, em suas diversas modalidades (psicológica ou física), tem sido amplamente estudada por ser motivo de preocupação para ações de políticas públicas de saúde. Sabe-se que várias mulheres são vítimas de violência todos os dias, principalmente no espaço familiar e doméstico - como indicado pela literatura especializada. O objetivo desta pesquisa foi analisar as alterações autobiográficas de mulheres vítimas de violência que buscaram a rede de atendimento público, também buscando compreender como a instituição de acolhimento para as vítimas influencia nesse processo de ressignificação da identidade. Foram entrevistadas três mulheres com idades entre 20 e 50 anos que buscaram atendimento num Centro de Referência da Mulher em Minas Gerais. As mulheres foram convidadas após o acolhimento fornecido pelo Centro e chamadas a participar de uma entrevista semiestruturada realizada numa universidade federal local, que teve como objetivo investigar as alterações autobiográficas ocasionadas pela violência. Os resultados foram analisados a partir do referencial teórico da psicanálise lacaniana e autores como Foucault e Goffman a partir da análise de conteúdo temático de Bardin. A partir dos dados coletados, foram constatadas diversas alterações na história e no autorreconhecimento da mulher vitimada, bem como a influência do Centro e do acolhimento neste processo. Entretanto, ainda se faz necessário o enriquecimento da literatura na área para fomentar melhorias no acolhimento destas vítimas.
\end{abstract}

Palavras-chave: autobiografia; violência contra a mulher; instituições; políticas públicas; psicanálise.

\begin{abstract}
The violence against women occurs in several forms (physical or psychological) and has been studied because it concerns the health public policies. It is know that many women are victims of violence every day, and the main space that it happens is in the domestic place, as it can be found in the literature. The present study aims to investigate how violence in its many forms cause autobiographical alteration in women who are victims of violence and sought the public care network, and also how the host institution help these victims in the reframing process. To this end, three women (ages between 20 and 50) who sought care at a Centro de Referência da Mulher in Minas Gerais/Brazil were interviewed. These women were asked after the reception given by the Centre to take part in a semi-structured interview conducted in a federal local university. The interview aimed to investigate the changes in the women autobiography after violence. The results were analyzed from the theoretical Lacanian psychoanalysis and authors like Foucault and Goffman from the thematic content analysis of Bardin. It was found various changes in the interviewees' history and self recognition of victimized women, as well as the influence of the host institution. Besides, the enrichment of research in the area is needed to drive improvements in health care to these victims.
\end{abstract}

Keywords: autobiography; violence against women; institutions; public policies; psychoanalysis.

\section{Carlos Felipe Lemes e Silva $a^{(1)}$ Rafael De Tilio ${ }^{(2)}$}

\author{
1) Psicólogo \\ 2) Professor Adjunto do curso de \\ graduação em Psicologia da Universidade \\ Federal do Triângulo Mineiro
}

Recebido em: 26/02/2014 Revisado em: $14 / 02 / 2015$ Aceito em: 25/02/2015 


\section{Resumen}

La violencia contra las mujeres en sus distintas modalidades (psicológica o física) ha sido muy estudiada debido la preocupación por las acciones de las politicas públicas de salud. Se sabe que muchas mujeres son víctimas de la violencia cada día sobre todo en el espacio familiar y doméstico. Según la literatura especializada el objetivo de esta investigación ha sido analizar las alteraciones autobiográficas de las mujeres víctimas de la violencia que procuraron la red pública de atención intentando comprender cómo la institución de acogida influye en el proceso de resignificación de la identidad. Se entrevistó a tres mujeres de edades entre 20 y 50 años que buscaron la atención en un Centro de Referencia a la Mujer en Minas Gerais/Brasil. Se invitó a las mujeres después de la acogida ofrecida por el Centro y les invitó a una entrevista semiestructurada realizada en una universidad federal local con el objetivo de investigar las alteraciones autobiográficas causadas por la violencia. Los resultados fueron analizados a partir del referencial teórico del psicoanálisis lacaniano y autores como Foucault y Goffman a partir del análisis de contenido de Bardin. Se constató diversas alteraciones de la historia y del auto reconocimiento de la mujer victimada así como la influencia del centro y de la acogida en este proceso. Sin embargo, todavía es necesario enriquecer la literatura en el área para fomentar la mejora de la acogida de estas víctimas.

Palabras clave: autobiografia; violencia contra la mujer; instituciones; politicas públicas; psicoanálisis.

\section{Résumé}

La violence contre les femmes sous toutes ses formes (psychologiques ou physiques) a été le point d'études et également source de préoccupation pour les actions de politiques publique de santé. On sait que beaucoup de femmes sont victimes d'agression chaque jour, surtout dans la famille et dans l'espace domestique. La présente étude vise à analyser les alterations autobiografique des femme victimes deviolence qui ont cherchéle réseu d'assistence publique. Ce travaille a aussi le but de déterminer comment l'établissement d'accueil aide les victimes dans le processus de resignifiance de l'identité. Trois femmes âgées entre 20 et 50 ans qui ont recherché des soins au Centre de Référence des Femmes dans Minas Gerais/Brésil ont été interrogés. Les femmes ont été invitées, après l'institution réaliser leur l'accueil, à participer, dans une université locale, d'un entretien semi-structuré qui vise à étudier les transformations biographiques causés par la violence soufferte. Les résultats ont été analysés d'après les théories de la psychanalyse lacanienne et selon auteurs comme Foucault et Gaffman à partir de l'analyse de contenu de thématique de Bardin. À partir des données collectées, on a vérifié qu'il y ait des plusieurs altérations dans les histoires raccontées et dans la reconnaissance de soi des femmes victimes de violence, ainsi que l'influence de l'institution d'accueil. Néanmoins, il y a encore le besoin d'amplifier la littérature dans le domaine pour conduire des améliorations dans l'assistence de ces victimes.

Mots-clés: autobiographie; violence contre les femmes; institutions; politiques publiques; psychanalyse.
A violência baseada no gênero, principalmente a cometida contra as mulheres, é um dos mais significativos problemas sociais e de saúde pública da atualidade, causando danos físicos, subjetivos e sociais devastadores para as vítimas e seus dependentes (Gadoni-Costa \& Dell'Aglio, 2010).

Estima-se que, no mundo e no Brasil, aproximadamente $35 \%$ das mulheres sofrem algum tipo de violência (Agência Patrícia Galvão, 2015). Muitos são os estudos que apontam para o crescimento da violência contra a mulher no Brasil nas últimas três décadas, situando-nos entre os dez países mais perigosos para uma mulher viver (Waiselfisz, 2011).

Ademais, segundo Waiselfisz (2011), os episódios e as vítimas de violência contra a mulher no Brasil possuem as seguintes características principais: ampla maioria de jovens (15-39 anos - 60\%) que são agredidas no ambiente doméstico $(68,8 \%)$ por pessoas conhecidas e com proximidade afetiva (pais, padrastos, esposos, companheiros, namorados e amigos - aproximadamente 80\%). Além disso, é importante ressaltar que a subnotificação da violência contra a mulher agrava ainda mais o problema (Kind, Orsini, Nepomuceno, Gonçalves, Souza, \& Ferreira, 2013; Schraiber, Barros, \& Castilho, 2013).

Teles e Melo (2012) argumentam que a violência contra a mulher, que é uma das expressões da violência de gênero, não deve ser justificada apenas a partir das características individuais dos envolvidos, devendo incluir o modo de funcionamento social. No Brasil, isso se materializa no autoritarismo, patriarcalismo, heteronormativismo e misoginia.

Assim, como argumenta Menezes (2002), mulheres que questionam posições tradicionais de gênero e de poder (masculino como dominador e feminino como submisso) tanto no espaço público como no espaço doméstico são alvo preferencial de violências reais ou simbólicas dos homens. Em suma, são as relações sociais e as relações de poder entre os gêneros que sustentam este tipo de violência.

Teles e Melo (2012) ainda argumentam que pesquisas empíricas apontam que a violência contra a mulher é cíclica e contínua, ou seja, geralmente as vítimas não conseguem alterar essa situação (Silva, Coelho, \& Caponi, 2007), já que permanecem ligadas ao agressor por laços de dependência afetiva e, por vezes, financeira. Esse ciclo da violência contra a mulher (situação de dependência que gera violência que, por sua vez, reforça a dependência) é um fenômeno amplamente relatado pela literatura científica (Costa, Moreira, Henriques, Marques, \& Fernandes, 2011; Rafael \& Moura, 2014).

Por isso, a dificuldade de desvencilhar-se do agressor e alterar sua realidade pode gerar mais sofrimento psíquico, criando ou aumentando a demanda por acolhimento pelos 
profissionais e instituições da saúde à mulher vítima de violência. O Brasil conta com mais de 300 delegacias especializadas no atendimento à mulher vítima de violência, além de leis especificadamente voltadas para o problema (Brasil, 2006, 2015).

Assim, nesta pesquisa, por alterações autobiográficas entendem-se as mudanças de significações da e na identidade e autoimagem destas mulheres ocorridas em decorrência da violência sofrida. Exposto isso, resgatar alguns autores da sociologia da identidade pode ser útil para compreender aspectos relacionados à violência contra a mulher e as mudanças causadas na sua autobiografia.

Goffman (2008), ao explorar a construção social da identidade individual a um nível microssociológico, observando a interação social nas ações cotidianas, enfatiza que a forma como cada indivíduo desempenha o seu papel determina a impressão causada nos outros em diferentes contextos (Cunha, 2003). Assim, considerando o escopo dessa pesquisa, é interessante considerar que a mulher vitimada reorganiza sua identidade após sofrer a violência.

Ainda neste sentido, Nunes e Torrenté (2009) descrevem, no contexto da teoria de identidade social de Goffman, como o indivíduo é posto à margem da sociedade por apresentar atributos que o torna diferente de outros e portador de características consideradas depreciativas. Os autores especificam que os atributos por si só não conduzem ao estigma, mas somente quando postos em uma "linguagem de relações" (p. 103).

Ou seja, o processo de estigmatização demanda um campo relacional, um contexto de interpretação dos atributos que conduz à normalidade ou à exclusão. Assim, quando a mulher é agredida (o que inclui sua passagem por instituições que produzem sua rotulação como mulher vitimada), isso cria demandas e questões para ela com potencial de mudar sua autobiografia.

Goffman (2008), ao apresentar o conceito de estigma, sua função e consequência para o indivíduo, discorre sobre aqueles confinados em padrões normalizados pela sociedade que, apesar de suas idiossincrasias ou características físicas, lutam para se emoldurar e constituir uma identidade social. Ademais, alerta para os sofrimentos que um estigma proporciona para o indivíduo, permitindo considerar como a violência pode levar a mulher, ao se esconder ou negar o acontecimento por temor das consequências, a reorganizar tais atributos a fim de se esquivar do estigma.

Ao conjecturar sobre as instituições totais, Goffman (2007) argumenta que no processo de admissão nestas instituições ocorre uma reconfiguração da identidade do indivíduo. O propósito destas instituições é o de (supostamente) recuperar o indivíduo nela inserido, entretanto, as cerimônias institucionais condicionam a subjetividade dos internados.

Essa interferência da instituição total no mundo interno do indivíduo também ocorre na rede de auxílio à mulher vítima de violência - salvo, claro, a particularidade de que a rede de auxílio não é exatamente uma instituição total e não existe um internamento da mulher. De qualquer maneira, a denúncia da vítima e o atendimento prestado pelas Delegacias da Mulher e pelos de Centro de Referência da Mulher tem potencial para gerar alterações autobiográficas na mulher vitimada, ou seja, a forma como a rede de atendimento à mulher vítima de violência funciona está correlacionada com a reformulação da identidade dos seus usuários.

Para compreender o processo de ressignificação da identidade, isto é, das alterações autobiográficas, o conceito de significante-mestre de Lacan (2007) é de grande valia. Lacan (1998) compreende a estruturação do significantemestre a partir da seguinte formulação: Um significante representa o sujeito para outro significante. Ou seja, para que se forme um sentido, um primeiro significante estabelece um espaço/distanciamento a fim de que seu (ou um sentido) diferencial se complemente pela a ausência do primeiro, não como seu oposto imediato, mas tomando seu lugar a fim de preencher sua ausência.

Zizek (1992) exemplifica esta díade com a oposição do dia e da noite:

Se a oposição do dia e da noite funciona como uma díade significante, não se trata, em absoluto, de uma simples alternância do dia e da noite. O dia vem à presença contra o fundo de sua própria ausência, cujo vazio é preenchido pela noite, e não com o fundo de sua relação complementar com a noite. (Zizek, 1992, p. 74)

A formação do sujeito ocorre a partir desta relação primordial do significante-mestre: Lacan (2007) constrói a lógica de que sem dois significantes não há um sujeito - “(...) em determinado ponto de ligação, entre o S1 [significante 1] e S2 [significante 2], é possível que se abra essa falha que se chama sujeito" (p. 93). Ou seja, o sujeito e sua identidade são constituídos a partir da relação entre posições identitárias (significantes) atribuídas pelo(s) (O) outros(s), cuja função pode ser exercida por uma instituição.

Este sujeito formado em relação ao Outro (o grande outro) como discurso do inconsciente se apresenta como o lugar “(...) de onde vêm as determinações simbólicas da história do sujeito" (Quinet, 2012, p. 23). Para Quinet (2012), o sujeito é indefinível, ou antes de mais nada, ele é a díade de seus significantes: “(...) ele é homem em relação à mulher, ele é médico em relação a um engenheiro" (p. 23).

Assim, o sujeito altera-se de significante em 
significante a partir da linguagem que compõe o Outro. Por analogia, mulheres vitimadas também são constituídas em relação ao significante-mestre que provém do Outro e suas consequências para sua história autobiográfica e suas alterações.

Diante do exposto, esta pesquisa teve como objetivo analisar alterações autobiográficas de mulheres vítimas de violência que buscaram a rede de atendimento.

\section{Método}

\section{Participantes}

Participaram desta pesquisa três mulheres que procuraram o Centro de Referência da Mulher Vítima de Violência de uma cidade de médio porte do interior de Minas Gerais após sofrerem violência e que aceitaram o acompanhamento psicológico durante o atendimento realizado por aquela instituição. Trata-se, portanto, de um estudo qualitativo a partir de três casos clínicos.

\section{Procedimentos de Coleta dos Dados}

$\mathrm{O}$ contato inicial com as participantes da pesquisa foi realizado num Centro de Referência da Mulher Vítima de Violência de uma cidade de médio porte do interior de Minas Gerais durante o período de setembro a novembro de 2013. Naquele momento foram convidadas a participar as mulheres que aceitaram o acompanhamento psicológico durante o atendimento realizado pela instituição, ou seja, após terem prestado queixa de violência às autoridades competentes.

$\mathrm{O}$ atendimento realizado pelo Centro de Referência da Mulher Vítima de Violência é interligado à Delegacia da Mulher e é caracterizado por um contato multiprofissional, abarcando aspectos jurídicos, sociais e psicológicos da mulher que busca ajuda. A vítima é recebida em um atendimento conjunto realizado pela assistente social e a psicóloga (acolhimento e escuta da denúncia) e, então, informada sobre seus direitos de denúncia e de processo judicial. Tambémé ofertada ajuda psicológica e de assistência social, sendo depois encaminhada para a advogada que auxilia novamente nos esclarecimentos jurídicos e o conduz ou não para a Delegacia onde as providências policiais são tomadas (boletim de ocorrência etc.).

Assim, o convite para a participação da pesquisa tomava lugar justamente durante o primeiro acolhimento no local, o que não necessariamente significa que era aquele o primeiro episódio de violência vivido pelas mulheres. Em outras palavras, o convite para participar da pesquisa ocorria enquanto era realizado o acolhimento institucional: as vítimas eram atendidas e indagadas se um dos pesquisadores poderia participar da conversa. Tal medida foi tomada para evitar nova exposição da mulher que chega em estado fragilizado na instituição, como também para tentar manter o bem-estar do sujeito durante o acolhimento. Após o atendimento realizado pela equipe do Centro de Referência, os pesquisadores convidavam a mulher vítima de violência para uma entrevista semiestruturada em outro momento e local (numa universidade federal local).

Essas entrevistas, realizadas individualmente e gravadas em áudio após autorização das participantes e que tiveram em média uma hora de duração cada, versavam sobre os seguintes conteúdos e temas: as razões pelas quais buscaram auxílio da Delegacia da Mulher e do Centro de Referência; a descrição do(s) episódio(s) de violência; a descrição das relações com o agressor e suas impressões sobre motivadores, causadores, consequências e responsáveis pela violência; suas impressões sobre o acolhimento realizado pelo Centro de Referência; e, principalmente, quais foram os impactos (físicos, subjetivos e sociais) de tanto ter sido vítima de violência de gênero como de ter procurado por aquelas instituições (Delegacia e Centro de Referência).

No total, os pesquisadores acompanharam doze atendimentos no Centro, mas apenas dez mulheres aceitaram o convite para nova entrevista, sendo que destas apenas três efetivamente compareceram à entrevista.

\section{Procedimentos de Análise dos Dados}

Os dados obtidos nas entrevistas foram analisados por meio da análise de conteúdo temático de Bardin (2010) e pelo referencial teórico da psicanálise, em especial a lacaniana, e por contribuições de autores com abordagem social como Goffman e Foucault.

\section{Disposições Éticas}

O projeto que deu origem a este estudo foi aprovado pelo CEP-UFTM (Protocolo 2642/2013). Os participantes formalizaram sua anuência por meio da assinatura do Termo de Consentimento Livre e Esclarecido. Não havia riscos nem benefícios imediatos previstos na participação desta pesquisa, a não ser a possibilidade das entrevistadas refletirem e ressignificarem as violências às quais foram expostas. Ademais, após a coleta dos dados todas as entrevistadas foram convidadas para novo encontro individual que pretendia apresentar os principais resultados da entrevista, mas nenhuma compareceu.

\section{Resultados e Discussão}

Os nomes reais das entrevistadas foram omitidos e substituídos por letras para assegurar o sigilo das suas 
identidades.

As três mulheres entrevistadas nesta pesquisa são: a (25 anos, solteira) mãe de uma filha de 7 anos, agredida pela atual namorada do ex-namorado e pela mãe de seu exnamorado; B (30 anos, casada) tem um filho de 4 anos e foi agredida pelo marido dentro de casa (quando da entrevista o marido não residia mais na casa, porém não existia nenhum processo de divórcio em andamento); C (45 anos, divorciada) e mãe de três filhos, ameaçada pelo filho mais velho e agredida fisicamente pela nora. Todas elas eram residentes em Uberaba, autodeclaradas brancas e pobres, porém empregadas, e com ensino fundamental completo (apenas $\mathrm{C}$ tinha ensino médio incompleto).

Apesar de apenas uma das entrevistadas ter sido vítima de violência por parte do companheiro homem e na unidade doméstica (B), todas as entrevistadas sofreram violência de gênero. Esse tipo de violência engloba tipos de agressões diversas (físicas, sexuais, morais, patrimoniais), causadas por situações diversas, podendo envolver pessoas diversas (familiares consanguíneos ou por afinidade; agregados rotineiros ou esporádicos), e ocorrem em espaços sociais diversos (coabitação ou não; no espaço doméstico ou no público) (Brasil, 2006).

Os resultados da pesquisa foram divididos em categorias após a análise de conteúdo temático de Bardin (2010). Assim, após leitura exaustiva do material coletado foram elencadas cinco categorias. As categorias foram nomeadas a partir de seus principais conteúdos: (a) alterações na autoestima; (b) alterações no sentimento de independência; (c) alterações corporais e depressão; (d) alterações nas relações sociais; e (e) alterações causadas pela instituição (Centro de Referência) e pelo acolhimento (entrevistas).

\section{Alterações na Autoestima}

Essa categoria apresenta alguns discursos das entrevistadas relativos às alterações autobiográficas na autoestima após a violência sofrida:

Me sinto feia e gorda, acho que estou ficando velha e não consigo mais perder peso ou ser como era antes, tenho vergonha até de dançar. (A)

Ele me chamava de burra e eu me defendia sempre (...) sempre me impunha mas agora não tenho mais forças e evito os conflitos(...) Não procuro me arrumar e não quero arrumar outro (relacionamento). (B)

Me sinto a pior criatura do mundo, porque eu acho que como eu sou mãe, eu acho que devia ser respeitada mesmo que não concorde com o que a mãe fala. Tem que ter respeito. (C)

Em todas as entrevistas realizadas, assim como nos atendimentos no Centro de Referência, uma das principais alterações autobiográficas acarretadas pela violência se relaciona com a autoestima do sujeito. Em pesquisa realizada por Vianna, Bomfim e Chicone (2006) com mulheres que foram vítimas de violência sexual, foi constatado um rebaixamento da autoestima das vítimas após a violência decorrente tanto do prejuízo físico da agressão quanto do medo de ser novamente agredida (mesmo quando o agressor se afastava).

Esses resultados relatados por Vianna, Bomfim e Chicone (2006) se assemelham ao relatados pelas entrevistadas: após sua agressão, apareceu um sentimento de baixa autoestima que prejudicava não somente sua saúde psíquica (dificuldades para dormir e ansiedade aumentada), mas também física, causando alterações de peso e psicossomatizações diversas.

A psicanálise entende que a autoestima está conectada ao narcisismo (uma avaliação subjetiva que o indivíduo tem do eu e do corpo imaginário). Cukiert e Priszkulnik (2002) destacam que, em Lacan, há fundamental importância da imagem do corpo para a formação do eu.

Cukiert e Priszkulnik (2002) ainda descrevem uma importante tese de destaque na teoria lacaniana: a constituição do sujeito a partir do Outro, por meio do qual o eu é levado a conhecer o mundo. Assim, apenas a título de esclarecimento, também é necessário salientar que na constituição da psique descrita por Freud, segundo Nasio (1991), há dois momentos distintos: o narcisismo primário (que acontece nos primeiros anos de vida na relação criança/ pais) e o secundário (que define a possibilidade do sujeito de criar investimentos em objetos externos através da maturidade psíquica e o destronamento do bebê no desejo da mãe), mas ambos são constituídos em relação e a partir de um Outro.

Tendo em vista a relação entre a autoestima feminina e o corpo, Nasio (1993), em diálogo com a teoria de Lacan, aponta que o corpo também é aquilo que o Outro vê e remete de mais imediato, ou seja: “(...) não a minha própria imagem do espelho, mas a imagem que me é remetida pelo outro, meu semelhante" (Nasio, 1993, p. 150). Diante disso, pode-se considerar como um acidente/incidente, no caso a violência, que apresenta novos significantes à mulher vitimada pode ser um disparador de alterações autobiográficas.

É importante também lembrar, para melhor distinguir do que se apresenta, que em quadros patológicos como da melancolia existe um sentimento de falta de estima de si (mas neste caso é feita uma autodegradação do eu e uma expectativa delirante de punição - Siqueira, 2007), o que não é necessariamente aplicável aos casos analisados nesta pesquisa, pois não foi notada nas entrevistas a busca por 
uma punição ou a aceitação passiva da violência.

Outro fator importante ligado à autoestima e a relação com o outro é a posição histórica e social de inferioridade da mulher em relação à dominação masculina. Para Foucault (1997), os homens exercem, por meio da violência, poder moral e político principalmente sobre as mulheres, reforçando a dominação masculina e a submissão feminina. Todavia, o que deve ser plenamente compreendido nestas situações não é uma simples disputa entre os sexos por meio da violência (os homens dominando as mulheres), mas sim que independente de quem a exerce (homens ou mulheres) a submissão delegada ao feminino é reiterada.

Por isso, mesmo que as entrevistadas tenham sido vítimas de violência perpetrada por homens (B) ou por mulheres (A e C), o impacto na autoestima é aparentemente o mesmo: a vítima mulher não deve se rebelar, deve se resignar com a agressão sofrida, pois as mulheres devem ser submissas ao poderio masculino, cronificando o rebaixamento da autoestima e dificultando possíveis reações e questionamentos.

\section{Alterações no Sentimento de Independência}

Essa categoria apresenta trechos das entrevistas nos quais são relatados consequências causadas pela violência contra mulheres que se consideravam independentes (financeira, psicológica e afetivamente) dos seus agressores:

Sempre fui forte e independente e não dependia de ninguém, mas agora parece que tô sem rumo, sem ninguém pra me ajudar. (A)

Cuidava da casa e do meu filho quase sozinha, tenho um negócio próprio e não preciso da ajuda de ninguém, mas agora [após a agressão] está tudo mais difícil para fazer sozinha. (B)

Criei meus filhos sozinha e não tive a ajuda de ninguém, agora parece que eu preciso e não sei como aceitar . Só busquei ajuda porque insistiram comigo. (C)

A independência da mulher e a possibilidade de não estar sujeita a outros para realizar suas ações diárias também é fator que segundo as entrevistadas passou por alterações, conforme explicitaram os trechos das entrevistas.

Narvaz e Nardi (2007) relembram que Foucault (1995) descrevia a dominação histórica de algumas minorias, entre estas as mulheres, mas defendia que buscassem sua liberdade. Tal incitamento teve influência na mentalidade feminina contemporânea e seu desejo pela independência, fator que lhes concede poder ao mesmo tempo em que a liberta da dominação de amarras sociais.

Esta posição de independência pode, para a psicanálise, se apresentar como um investimento para a idealização:
"[...] o objeto $a$ que o neurótico se leva a ser em sua fantasia cai-lhe quase tão mal quanto plainas num coelho" (Lacan, 2005, p. 60). Ou seja, as mulheres que se apresentaram como independentes e fortes antes da violência sofrida se desfazem quando esta imagem é colocada à prova de forma tão brutal. O relato da entrevistada $\mathrm{A}$, citado anteriormente, é oportuno por evidenciar esse movimento.

Também segundo a formulação lacaniana (de que o sujeito aparece em uma falha da ligação entre dois significantes que se alternam na função de significantemestre) permite sugerir que a presença desse questionamento da identidade constituída até então pela vítima - a nova sobreposição de significantes - remonta uma perspectiva diferente para sua cadeia de significantes, sua nova falha (Lacan, 2007)

Assim, a entrada na rede de acolhimento também possibilita para a vítima um contato mais evidente com essa nova posição passiva (de dependência ou de questionamento da plena independência), da busca por ajuda externa em um meio que não seja somente familiar ou de amigos.

Goffman (2007) auxilia na compreensão desse fenômeno de mudança no indivíduo quando indica que os próprios mecanismos de admissão das instituições já trabalham para formatar o indivíduo a um estatuto prédisposto. Observa-se que o próprio termo Delegacia da Mulher infere na mulher um papel de vítima.

Entretanto, a realidade do trabalho conjunto entre Delegacia e Centro de Referência da Mulher é de que o acolhimento multiprofissional auxilia na quebra desse primeiro estigma vivenciado pela mulher, demonstrando para esta que não deve haver vergonha na busca por ajuda e que a mesma não funcionará como uma vingança ou retaliação contra seu agressor, mas sim como uma proteção para a vítima.

\section{Alterações Corporais e Depressão}

Essa categoria foi constituída porque se constatou nas falas e nos sintomas relatados pelas mulheres uma relação entre violência e processos de ressignificação autobiográfica corporal:

Eu era dançarina de uma banda de baile, tinha um corpo lindo, hoje tô gorda e me acho feia, perdi vontade até de dançar. (A)

Perdi muito peso desde a agressão (7 quilos) e também estou muito desleixada com minha aparência, faz tempo que não faço as unhas ou arrumo o cabelo. (B)

Perdi peso mas é até coisa boa, tenho pressão alta , mas não durmo direito e tenho medo de ser agredida de novo, também estou muito mais ansiosa. (C) 
Para Nascimento, Próchono e Silva (2012), o corpo da mulher é atualmente tratado como um objeto sob-regência do capitalismo. A sociedade de consumo, do espetáculo e do narcisismo, que por meio da mídia, influencia os hábitos de consumo e também e a subjetividade feminina.

Assim, o (próprio) corpo é tratado como objeto de consumo transformando a relação do sujeito consigo mesmo e, consequentemente, com sua subjetividade, apontando "[...] que o homem passou a ter e deixou de ser um corpo" (Nascimento et al., 2012). Tal implicação sobre o corpo da mulher foi perceptível em alguns momentos das entrevistas, nominalmente no relato anterior de A.

Freud e Breuer (1995) trouxeram luz à subjetividade do corpo feminino em seus trabalhos sobre as histéricas, revelando como estas utilizavam o corpo como uma metáfora para o inconsciente, mostrando que o corpo é vivenciado pela experiência do inconsciente e como este influencia a saúde física e psíquica.

Assim, a alteração do corpo aparece como uma importante mudança vivenciada pelas vítimas após a violência sofrida. Durante as entrevistas, foi possível constatar essa modificação de forma clara e objetiva por meio dos relatos, pois as respostas sempre convergiram para a apresentação de uma nova realidade corporal - vide o relato de $\mathrm{B}$.

O ganho ou perda de peso é comum entre os relatos: dentre as entrevistadas, duas tiveram perda significativa de peso enquanto uma ganhou peso em mesma intensidade. Este fenômeno de alteração no peso pode ser relacionado às somatizações (perda do sono, sintomas físicos da ansiedade generalizada) sofridas pelo trauma da violência, bem como com o convívio com a ideia (e medo) de ser novamente agredida.

Pode-se definir somatização como um "[...] distúrbio corporal que surge como expressão de uma neurose profundamente assentada, uma doença do inconsciente" (Neto \& Marcheti, 2009, Somatização, para. 1). Desta forma, o sintoma da alteração de peso possui relação com a violência sofrida, ou seja, seria uma tentativa do inconsciente falar sobre o sofrimento relatando-o no corpo (Freud, 2006b). Já em Lacan, para Dias (2006), a ideia de sintoma vem ao encontro de sua principal formulação: o inconsciente é estruturado como linguagem a ser decifrada.

Assim, na tentativa de compreender a presença das somatizações nos casos entrevistados, também é importante ressaltar outro fator comum, entre eles: a presença de sintomas ou quadros depressivos, relatados por C ("me sinto a pior pessoa do mundo... depois que tudo começou tenho muito medo, durmo pouco e perdi peso") e por A ("choro muito e ando muito mais nervosa, até minha filha percebeu").
Em primeiro lugar, a relação entre depressão e a posição de vítima é pautada por um fator comum, que se resume na perda ou finalização de um relacionamento, seja ele amoroso ou familiar. Todas as mulheres entrevistadas têm em sua história de agressão alguma perda de relacionamento ocasionada pela violência; com essa perda, alterações autobiográficas são comuns ao quadro depressivo (Freud, 2006a), tais como: queixas somáticas, baixa autoestima, alteração do sono e do humor.

\section{Alterações nas Relações Sociais}

Essa categoria apresenta trechos das entrevistas que condensam as dificuldades das entrevistadas em continuar exercendo suas habituais relações sociais após sofrerem agressões:

Quase não saio mais, fico com minha filha mas ela também vê que estou triste; terminei meu namoro atual e não sei se quero outro. (A)

Achava que era uma mulher muito forte e independente mas hoje eu vejo que preciso de ajuda. Também estou gostando de ficar sozinha, mais que antes. (B)

Ando com mais medo das pessoas, medo de ser agredida novamente, não gosto mais de ficar sozinha em casa como ficava antes disso tudo acontecer. (C)

Uma consequência igualmente observada é uma nova posição das entrevistadas frente as suas relações pessoais e sociais, seja essa nova posição uma alteração em seu modo de se portar frente a outras pessoas, seja um novo pensamento sobre a antiga postura social. Isso fica evidenciado em falas como as de C.

Para melhor compreender este fato, Goffman (2008) argumenta que o estigma pode induzir a pessoa a exercer comportamentos defensivos ou de estereotipia do grupo, ocasionando uma nova apresentação perante aos outros. Ferreira (2012) auxilia a averiguar essa nova constituição da imagem social, relembrando o conceito de eu civil na teoria de Goffman: uma lenta elaboração que o indivíduo passa para criar a imagem de si mesmo a partir das relações com outros.

Tal imagem pode ser alterada por influência do meio social, afetivo e institucional, apresentando outros significados para os indivíduos. Aqui é estabelecido um claro alerta de como a violência psicológica (também) sofrida por essas mulheres pode resultar na alteração na autoimagem e na autobiografia.

Após a violência sofrida algumas das mulheres passaram a relatar sentimentos de desconfiança de outras pessoas de seu ciclo de convívio, e também passaram a procurar ficar mais tempos sozinhas em uma espécie de solidão, como 
exemplificou B. Nos outros casos, as alterações no convívio social foram mínimas, sendo restritas apenas às interações com seu agressor ou com alguém que lembre a violência ocorrida - o que já é um grave dano à autonomia dessas mulheres.

Outro âmbito de apreciação é o trauma causado pela violência. Para compreender a relação existente entre os dados coletados e o trauma da violência novamente, lançase expediente da teoria psicanalítica lacaniana: o trauma se constitui como uma impossibilidade de suportar uma excitação proveniente de uma situação inassimilável para o sujeito, e isso tem um efeito perturbador na presença/ reatualização do agente traumático (Meshulam-Werebe, Andrade, \& Delouya, 2003).

Assim, o trauma causado pela violência sofrida (evidenciado pelo aumento de ansiedade e pelo medo de repetição da agressão), constitui fator de alteração autobiográfica das entrevistadas. Disseram elas ao longo das entrevistas que a violência sofrida causou mudanças nas maneiras como veem a vida e se relacionam com outras pessoas, ou seja, que a violência impactou a maneira pela qual (suas identidades e biografias) eram e agora são.

\section{Alterações Causadas pela Instituição (Centro de Referência) e pelo Acolhimento (Entrevistas)}

Essa categoria pretendeu relatar como as entrevistadas atribuíam sentidos às influências das intervenções propostas pelo Centro de Referência da Mulher Vítima de Violência e pelas entrevistas realizadas pelos pesquisadores, visto que esses dois momentos poderiam também servir como episódios de ressignificação autobiográfica da violência sofrida:

Com esse atendimento (acolhimento) eu penso nas coisas e tenho uma ajuda maior pra conseguir viver tudo isso. É muito difícil mas eu preciso de ajuda. Agora eu compreendo a importância de não ficar sozinha nesses problemas. (A)

Na instituição eu fiz o boletim de ocorrência, mas não sei falar se algo mudou. Acho que um pouco de vergonha e também um sentimento de que alguma coisa acabou na minha vida. (B)

Acho que essa ajuda (acompanhamento psicológico) pode me ajudar sim mas ainda estou muito perdida e sem rumo após agressão. As coisas que a gente fala que pode prejudicar nossa família a gente não fala pra ela mas fala pra um estranho. (C)

A Rede de Acolhimento também funciona como um agente ativo para permitir novas perspectivas para as mulheres vítimas de violência. Ao contrário das instituições totais descritas por Goffman (2007), a rede de acolhimento não oferece um regime de atendimento de internação e não distancia a paciente/usuária dos funcionários/profissionais do local.

A alteração destacada se dá de uma maneira dinâmica no acolhimento oferecido pela instituição: mesmo o sujeito se adequando parcialmente à imagem de mulher vítima da violência por estar em contato com uma instituição policial e jurídica especializada para isso, o acolhimento fornece meios para uma ressignificação de todo o processo de violência sofrida.

Apesar de o acolhimento oferecido pela instituição ofertar meios para a melhoria do estado da mulher que busca ajuda, foi usual entre as entrevistadas o relato do medo ao buscar ajuda: quando levadas a denunciar seu agressor as vítimas temem uma retaliação por parte do mesmo e também tem receio da exposição social causada pela denúncia.

Outra consequência para as alterações autobiográficas das vítimas de violência que procuram pelo Centro é a própria maneira pela qual ele funciona: um meio de contato com a (nova) realidade de agredida ou vitimada. Isso ocorre porque a instituição atribui o estigma da violência às vítimas demandantes dos seus serviços: passa-se a ser uma mulher vitimada. Pode-se observar tal fator no supracitado trecho da entrevista de B.

Neste ponto, as entrevistas também se revelaram como possíveis momentos de ressignificação da violência. A escuta proporcionada pelos pesquisadores às entrevistadas proporcionou um contato com a queixa das mesmas, não somente sobre a violência, mas também possibilitou compreender seu estado/papel de vítima e as consequências desta violência/posição para sua saúde mental.

O espaço de confidencialidade proporcionado pelas entrevistas mostrou-se de grande importância para que as vítimas pudessem recontar suas histórias e refletir sobre as mesmas sem que fossem postas sob um peso jurídicolegalista, tal como ocorria na Delegacia e no Centro. Isso pode ser observado quando as entrevistadas são questionadas sobre como poderiam ser ajudadas neste momento, sendo emblemática a resposta supracitada de $\mathrm{C}$.

\section{Considerações Finais}

A análise dos dados constatou que as alterações autobiográficas das mulheres vítimas de violência são influenciadas pelas suas vivências de agressão, pela entrada nas instituições de acolhimento (Delegacia da Mulher e Centro de Referência), e pela entrevista realizada.

A investigação acerca dos significantes e das modificações autobiográficas sofridas pelas vítimas revelou novas formas de viver e compreender essas mulheres e 
suas histórias, resultado da agitação na cadeia significante e consequente reestruturação do sujeito. A maneira com que a autoimagem e a autobiografia se modificam por meio de todo o processo é evidência desta alteração de significantes e também da posição em relação ou Outro.

A violência sofrida causa não somente lesões físicas, mas também a transferência de sentimentos e sofrimento psicológico resultante em sintoma corporal: a mulher vítima é obrigada a conviver com sua nova imagem (estigmatizada como vítima de violência de gênero) e com a lembrança da agressão, e adoece física e mentalmente. Tal fenômeno é exemplificado pelo quadro depressivo apresentado pela maioria das entrevistadas.

O papel da instituição (Centro de Referência) influencia também na renovação autobiográfica e de identidade da mulher vitimada: a rede de acolhimento ao proporcionar o contato com a realidade do estigma da mulher agredida permite o remanejamento dos e nos significantes por meio da revivência da situação e pelo medo de vingança ou de nova agressão. Além disso, a instituição favorece por meio do acolhimento e da instrução judicial um espaço para que a mulher comece a se reestruturar e se sensibilizar para aceitar outros tipos de atendimentos e auxílios.

O espaço reservado para a entrevista, que também é um acolhimento afetivo, constatou algumas alterações na autobiografia da vítima da mesma forma que as outras intervenções realizadas. Embasados na teoria psicanalítica o acolhimento e a entrevista foram realizados e trouxeram à tona novas representações e significantes e possibilidades de interpretações para as situações que as entrevistadas estavam vivenciando.

Uma dificuldade encontrada na coleta de dados foi a resistência das mulheres demandantes do Centro de Referência para serem entrevistadas: dentre 10 mulheres que mostraram interesse em conceder entrevistas, apenas três efetivamente o fizeram, e nenhuma delas retornou ao encontro final para a revolução dos resultados.

Alguns fatores podem ter contribuído para isso, por exemplo, o fato dos pesquisadores/entrevistadores serem do sexo masculino, podendo acarretar transferências das emoções da agressão (delegando-as novamente a um papel de submissão e de fragilidade) atualizáveis na imagem dos pesquisadores. Mesmo nas entrevistas foi possível notar a resistência e dificuldade das mulheres em falar sobre a violência sofrida, motivo pelo qual se optou por conduzir as entrevistas em forma de acolhimento em psicoterapia breve para minimizar tal fato.

O fator culpa (por ter vivenciado a agressão e/ou mesmo imaginariamente tê-la causado) foi propositalmente excluído da análise das alterações autobiográficas por diversas razões, mas principalmente porque não foi possível um aprofundamento deste tema nas entrevistas para investigar o papel das vítimas nas agressões e tampouco sugerir/subentender que elas possuíam responsabilidades por sua ocorrência, o que certamente duplicaria a violência sofrida.

Todavia, de maneira geral, durante as entrevistas foi possível inferir por meio da escuta da história da violência sofrida um subjacente sentimento de culpa por parte das mulheres e que não era aceito por elas (fato interessante porque possibilita alterações na autobiografia) - por não ser esse objetivo da pesquisa, esse assunto não foi aprofundado.

Neste sentido, a literatura científica sobre violência contra a mulher apesar de sua expressividade ainda necessita de mais investigações que relacionem teoria psicanalítica com abordagem social e, e não somente clínica e interpretativa calcada no indivíduo. Isso é importante porque a violência de gênero não se restringe aos aspectos individuais dos envolvidos.

Considerando outra vertente de análise, a pesquisa procurou destacar a importância da instituição (Centro de Referência) na produção de alterações autobiográficas nas mulheres vitimadas. Isso ocorre porque o sujeito ao participar de uma instituição é atingido pelos significantes institucionais e institucionalizados e, por vezes, também por suas estigmatizações.

Por fim, e em destaque, há de ressaltar que o Centro de Referência da Mulher que acolhe mulheres vitimadas e que serviu de suporte para essa pesquisa funciona de maneira adequada. Todavia, sua prestação de serviços é dificultada devido às precárias condições físicas (falta de salas de atendimento). Além disso, as relações entre a Delegacia de Defesa da Mulher e o Centro de Referência da Mulher, que funcionam no mesmo espaço físico, poderiam ser melhoradas para que algumas angústias e frustrações das vítimas/usuários sejam abrandadas.

Fundamental e necessário é também dar maior importância e destaque ao sentimento e capacidade de revolta das entrevistadas por terem sido agredidas. Isso funcionaria como ponto de partida para novas alterações autobiográficas e como motivo para a busca por ajuda e denúncia do agressor. A incapacidade de se revoltar é preocupante porque reveladora de uma posição de extrema inferioridade em relação ao agressor e a dominação masculina sob a qual o sujeito (vitimado) vive.

Em suma, a violência física ou psicológica tem poder de gerar alterações autobiográficas nas mulheres, sejam elas negativas (danos, sintomas etc.) ou positivas (se é que podemos utilizar essa expressão; tais como reformulações nos modos de viver e de responder à violência impetrada). Apesar do pouco tempo para uma escuta clínica aprofundada nesta pesquisa foi possível constatar vestígios de alterações 
nos significantes das mulheres atendidas e entrevistadas.

Entretanto, ainda se faz necessário mais pesquisas nesse campo de investigação, em especial visando práticas e intervenções para auxiliar sujeitos vitimados a viverem melhor e com mais dignidade e que, quiçá, rompam com violências que nem sempre puderam optar participar.

\section{Referências}

Agência Patrícia Galvão. (2015). ONU aponta que $35 \%$ das mulheres em todo o mundo já sofreram violência (09/03/2015). Recuperado de http:// agenciapatriciagalvao.org.br/violencia/onu-apontaque-35-das-mulheres-em-todo-o-mundo-ja-sofreramviolencia/

Bardin, L. (2010). Análise de Conteúdo. Lisboa, Portugal: Edições 70.

Brasil. (2006). Presidência da República. Casa Civil, Subchefia para Assuntos Jurídicos. Lei $n^{\circ} 11.340$ de 07 de Agosto de 2006. Brasília/DF. Recuperado de http:// www.planalto.gov.br/ccivil_03/_ato2004-2006/2006/ lei/111340.htm

Brasil. (2015). Presidência da República. Casa Civil, Subchefia para Assuntos Jurídicos. Lei $n^{\circ} 13.104$ de 09 de março de 2015. Brasília/DF. Recuperado de http:// www.planalto.gov.br/ccivil_03/_Ato2015-2018/2015/ Lei/L13104.htm

Costa, A. M. da, Moreira, K. de A. P., Henriques, A. C. P. T., Marques, J. F., \& Fernandes, A. F. C. F. (2011). Violência contra a mulher: Caracterização de casos atendidos em um Centro Estadual de Referência. Rev Rene, 12(3), 627-635.

Cukiert, M., \& Priszkulnik, L. (2002) Considerações sobre o eu e o corpo em Lacan. Estudos em Psicologia, 7(1), 143-149.

Cunha, S. M. (2003). Estigma: Notas Sobre a Manipulação da Identidade Deteriorada. Recuperado de http:// maracujah.net/files/doc/estigma.pdf

Dias, M. G. L. V. (2006). O sintoma: de Freud a Lacan. Psicologia em estudo, 11(2), 399-405.

Ferreira, S. M. (2012). Polissemia do conceito de instituição: Diálogos entre Goffman e Foucault. Estudos Contemporâneos da Subjetividade, 2(1), 74-85.

Foucault, M. (1995). O Sujeito e o Poder. In P. Rabinow, \& H. Dreyfus, Michel Foucault. Uma trajetória filosófica. Para além do estruturalismo e da hermenêutica. Rio de Janeiro: Forense Universitária.
Foucault, M. (1997). A mulher/os rapazes: História da sexualidade. In História da Sexualidade (Vol. 3). Rio de Janeiro: Paz e Terra.

Freud, S. (2006a). Luto e melancolia. In J. Strachey (Ed.), Edição Standard Brasileira das Obras Psicológicas Completas de Sigmund Freud (Vol. 14). Rio de Janeiro: Imago. (Originalmente publicado em 1915)

Freud, S. (2006b). Os caminhos da formação dos Sintomas. In J. Strachey (Ed.), Edição Standard Brasileira das Obras Psicológicas Completas de Sigmund Freud (Vol. 16). Rio de Janeiro: Imago. (Originalmente publicado em 1916)

Freud, S., \& Breuer, J. (1995). Estudos sobre a histeria. In J. Strachey (Ed.), Edição Standard Brasileira das Obras Psicológicas Completas de Sigmund Freud (Vol. 2). Rio de Janeiro: Imago. (Originalmente publicado em 1895)

Gadoni-Costa, L. M., \& Dell'Aglio, D. D. (2010). Mulheres em situação de violência doméstica: vitimização e coping. Gerais: Revista Interinstitucional de Psicologia, 2(2), 151-159.

Goffman, E. (2007). Manicômios, Prisões e Conventos. Brasil: Editora Perspectiva.

Goffman, E. (2008). Estigma - notas sobre a manipulação da identidade deteriorada. Brasil: JZE.

Kind, L., Orsini, M. de L. P., Nerpomuceno, V., Gonçalves, L., Souza, G. A. de, \& Ferreira, M. F. F. F. (2013). Subnotificação e (in)visibilidade da violência contra mulheres na atenção primária à saúde. Cad. Saúde Pública, 29(9), 1805-1815.

Lacan, J. (1998). Função e campo da fala e da linguagem em psicanálise. In J. Lacan, Escritos. Rio de Janeiro: JZE.

Lacan, J. (2005). Seminário 10: A Angústia. Rio de Janeiro: JZE.

Lacan, J. (2007). Seminário 17: O avesso da Psicanálise. Rio de Janeiro: JZE.

Menezes, M. I. C. B. B. (2002). Mulher, poder e subjetividade. Revista Mal-Estar e Subjetividade, 2(2), $59-85$

Meshulam-Werebe, D., Andrade, M. G. O., \& Delouya, D. (2003). Transtorno de stress pós-traumático: O enfoque psicanalítico. Revista Brasileira de Psiquiatria, 25(Supl I), 37-40.

Narvaz, M., \& Nardi, H. C. (2007). Problematizações feministas à obra de Michel Foucault. Revista Mal 
Estar e Subjetividade, 7(1), 45-70.

Nascimento, C. M., Prochno, C. C. S. C., \& Silva, L. C. A. (2012). O corpo da mulher contemporânea em revista. Fractal: Revista de Psicologia 24(2): 385-404.

Nasio, J. D. (1991). A criança magnifica da psicanálise: $O$ conceito de sujeito e objeto na teoria de Jacques Lacan. Rio de Janeiro: JZE.

Nasio, J. D. (1993). Cinco lições sobre a teoria de Jacques Lacan. Rio de Janeiro: JZE.

Neto, J. G., \& Marchetti, R. L. (2009). A histeria como comportamento. Recuperado de http://www. medicinanet.com.br/m/conteudos/revisoes $/ 2325 /$ histeria_somatizacao_conversao_e_dissociacao.htm.

Nunes, M., \& Torrenté, M. (2009). Estigma e violências no trato com a loucura: Narrativas de centros de atenção psicossocial, Bahia e Sergipe. Revista de Saúde Pública, 43(Suppl. 1), 101-108.

Quinet, A. (2012). Os outros em Lacan. Rio de Janeiro: JZE.

Rafael, R. de M. R., \& Moura, A. T. M. S. de (2014). Violência contra a mulher ou mulheres em situação de violência? Uma análise sobre a prevalência do fenômeno. J Bras Psiquiatr.,63(2):149-53.

Schraiber, L. B., Barros, C. R. dos S., \& Castilho, E. A. de. (2010). Violência contra as mulheres por parceiros íntimos: Usos de serviços de saúde. Rev Bras Epidemiol, 13(2), 237-245

Silva, L. L., Coelho, E. B. S., \& Caponi, S. N. C. (2007). Violência silenciosa: Violência psicológica como condição da violência física doméstica. Interface (Botucatu), 11(21), 93-103.

Siqueira, E. S. E. (2007). A depressão e o desejo em psicanálise. Estudos e Pesquisa em Psicologia, 7(1), 71-80.

Teles, M. A. de A., \& Melo, M. (2012). O que é violência contra a mulher. São Paulo: Editora Brasiliense.

Vianna, L. A. C., Bomfim, G. F. T., \& Chicone, G. (2006). Auto-estimademulheres que sofreram violência. Revista Latino-Americana de Enfermagem, 14(5), 695-701.

Waiselfisz, J. J. (2011). Mapa da Violência 2012. Os novos padrões da violência homicida no Brasil. São Paulo: Instituto Sangari.

Zizek, S. (1992). Eles não sabem o que fazem: O sublime objeto da ideologia. Rio de Janeiro: JZE.

\section{Endereço para correspondência:}

Carlos Felipe Lemes e Silva

Endereço: Rua São Francisco de Assis, no ${ }^{\circ}$, Bairro

Abadia. Uberaba/MG. - CEP 38026-210

E-mail: carloslemes.uftm@gmail.com

\section{Endereço para correspondência:}

Rafael De Tilio

Endereço: Avenida Getúlio Guaritá, nº 159, sala 320,

Bairro Abadia. Uberaba/MG. - CEP38025-440,

E-mail: rafaeldetilio.uftm@gmail.com 